(C) 2016 IEEE. Personal use of this material is permitted. Permission from IEEE must be obtained for all other uses, in any current or future media, including reprinting/republishing this material for advertising or promotional purposes, creating new collective works, for resale or redistribution to servers or lists, or reuse of any copyrighted component of this work in other works. 


\title{
Detection of Partial Demagnetization Fault in PMSMs Operating under Nonstationary Conditions
}

\author{
Chao Wang ${ }^{1}$, Miguel Delgado ${ }^{2}$, Luis Romeral ${ }^{2}$, Zhe Chen $^{1}$, Frede Blaabjerg ${ }^{1}$, Fellow, IEEE, and Xiao Liu ${ }^{1}$ \\ ${ }^{1}$ Department of Energy Technology, Aalborg University, 9220, Aalborg, Denmark \\ ${ }^{2}$ Department of Electronic Engineering, Universitat Politecnica de Catalunya, 08222 Terrassa, Barcelona, Spain
}

\begin{abstract}
Demagnetization fault detection of in-service Permanent Magnet Synchronous Machines (PMSMs) is a challenging task because most PMSMs operate under nonstationary circumstances in industrial applications. A novel approach based on tracking characteristic orders of stator current using Vold-Kalman Filter is proposed to detect the partial demagnetization fault in PMSMs running at nonstationary conditions. Amplitude of envelope of the fault characteristic orders is used as fault indictor. Experimental results verify the superiority of the proposed method on partial demagnetization online fault detection of PMSMs under various speed and load conditions.
\end{abstract}

Index Terms-Demagnetization, fault detection, nonstationary, permanent magnet synchronous motors (PMSMs), Vold-Kalman filtering (VKF)

\section{INTRODUCTION}

$\mathrm{P}$ ARTIAL demagnetization of Permanent Magnet Synchronous Motors (PMSMs), may lead to a progressive performance degradation or even arouse catastrophic failures [1-2]. Thus, early and accurate detection of the partial demagnetization fault is of great significance for the operation $\&$ maintenance of PMSMs and associated machinery and electromechanical systems. So far, the commonly monitored parameters for Partial Demagnetization Fault Detection (PDFD) are stator current [3-5], zero sequence voltage component [6], Back-EMF [7], shaft trajectory [8] and vibration [9]. Following the classical motor current signature analysis approach, the characteristic demagnetization fault frequencies, $f_{d}$, are $f_{0}\left(1 \pm \frac{k}{P}\right)$, where $f_{0}$ is the electrical fundamental frequency, $k$ is an integer, and $P$ is the number of pole pairs [3-8,10-11,13-14]. Thus, the PDFD under stationary conditions of speed and torque is commonly based on the identification of such characteristic fault frequencies throughout the spectrum analysis, estimated by means of conventional Fourier Analysis (FA) [6-8]. All frequency components of the analyzed signal could be revealed via FA, which is only suitable for analysis under stationary conditions, the frequencies changing with time could not be tracked. However, most PMSMs operate under nonstationary conditions in industrial applications. For instance, PMSMs in wind power applications rotate at variable speed in order to extract the maximum power from wind [12]. For PDFD under nonstationary conditions, classical spectrum analysis is invalid due to evident frequency aliasing. Hence, the joint timefrequency domain analysis represents the most suitable solution for PDFD under nonstationary conditions, including mainly Wavelet Transform (WT) [3, 13], Hilbert-Huang Transform (HHT) [4] and Choi-William Distribution (CWD) [14]. The WT and HHT methods are based on the analysis of

Manuscript received Nov. 6 2015. Corresponding author: C. Wang (email: chw@et.aau.dk).

Color versions of one or more of the figures in this paper are available online at http://ieeexplore.ieee.org. different frequency bands, however, the frequency band of the fault related orders may cross over several bands in drastic changing operation conditions, which may affect the analysis of the fault characteristics. The CWD is a good method for global time-frequency representation of the fault related signatures, however, the global representation is time consuming and unnecessary because only the characteristic fault related harmonics are required.

A novel methodology based on the tracking of the characteristic demagnetization fault orders of stator current by means of Vold-Kalman Filter (VKF) is presented for PDFD of PMSMs running under nonstationary conditions. The rest of this paper is organized as follows, section II describes the principle of VKF briefly, experimental setup of partial demagnetization of a PMSM is presented in section III, in section IV, the PDFD results under various nonstationary scenarios using the proposed VKF are presented and analyzed, section $\mathrm{V}$ draws the conclusions.

\section{ORder Tracking USING VOLD-KaLman FILTER}

VKF, proposed by Håvard Vold in 1993 based on Kalman filtering, could track the multiple harmonic orders simultaneously. The advantages including ability of handling time-varying signal, no phase deviation and capability of extracting orders in time domain, make VKF based order tracking feasible for the PDFD of PMSMs under nonstationary conditions [15-16]. The principle of VKF based order tracking is briefly introduced in this section.

Suppose $\boldsymbol{x}=\left[\begin{array}{llll}x(1) & x(2) & \ldots & x(N)\end{array}\right]^{T}$ is the tracked harmonic order and the differential order is 3 , then structure equation is,

$$
A=\left[\begin{array}{ccccccccc}
1 & -3 & 3 & -1 & \ldots & 0 & 0 & 0 & 0 \\
0 & 1 & -3 & 3 & \ldots & 0 & 0 & 0 & 0 \\
\ldots & \ldots & \ldots & \ldots & \ldots & \ldots & \ldots & \ldots & \ldots \\
0 & 0 & 0 & 0 & \ldots & 1 & -3 & 3 & -1
\end{array}\right] \text {, }
$$




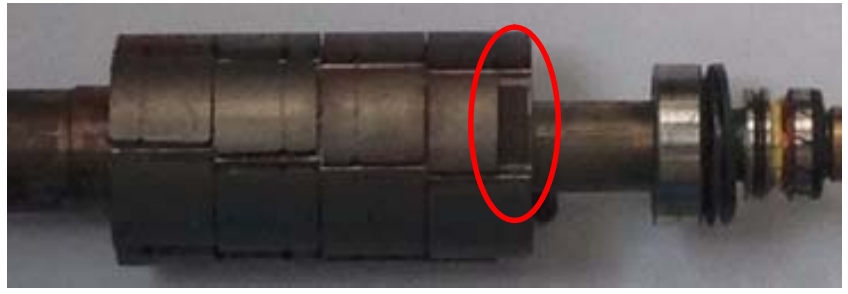

(a)

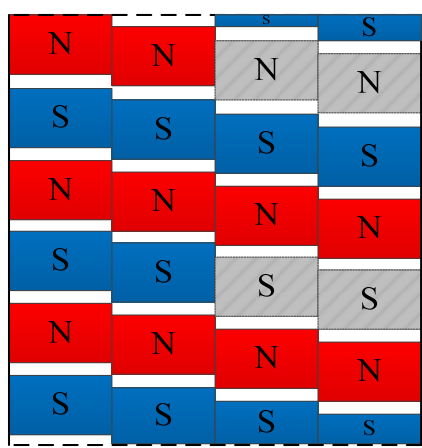

Partially demagnetized part

(b)

Fig. 1. Experimental setting of partial demagnetization of one pole pair. (a) Damaged magnet of a surface-mounted PMSM. (b) Schematic of 50\% partial demagnetization scheme of one pole pair in the unfolded magnet array.

$\boldsymbol{\varepsilon}=\left[\begin{array}{llll}\varepsilon(1) & \varepsilon(2) & \ldots & \varepsilon(N-3)\end{array}\right]^{T}$ is the non-homogenous term.

Data equation is,

$$
y=C x+\eta
$$

where $\boldsymbol{y}=\left[\begin{array}{lllll}y(1) & y(2) & \ldots & y(N)\end{array}\right]^{T}$ is the measurement, $\boldsymbol{\eta}=\left[\begin{array}{llll}\eta(1) & \eta(2) & \ldots & \eta(N)\end{array}\right]^{T}$ is the measurement error and noise.

$$
\boldsymbol{C}=\left[\begin{array}{cccc}
e^{j \Theta(1)} & 0 & \ldots & 0 \\
0 & e^{j \Theta(2)} & \ldots & 0 \\
\ldots & \ldots & \ldots & \ldots \\
0 & 0 & \ldots & e^{j \Theta(n)}
\end{array}\right]
$$

is the output matrix,

$$
\Theta(n)=\sum_{i=1}^{n} \omega(i) \Delta t
$$

$\omega(i)$ is discrete angular frequency, $\Delta t$ is sampling interval.

Based on least square method, the quadratic sum of $\varepsilon$ and $\eta$ should be minimum, thus the cost function

$$
J=r^{2} \boldsymbol{\varepsilon}^{T} \boldsymbol{\varepsilon}+\boldsymbol{\eta}^{T} \boldsymbol{\eta}=r^{2} \boldsymbol{x}^{T} \boldsymbol{A}^{T} \boldsymbol{A} \boldsymbol{x}+\left(\boldsymbol{y}^{T}-\boldsymbol{x}^{*} \boldsymbol{C}^{*}\right)(\boldsymbol{y}-\boldsymbol{C} \boldsymbol{x})
$$

$r$ is weighting coefficient, superscript * stands for complex conjugate. By derivation operation, we get the tracked order,

$$
\boldsymbol{x}=\left(r^{2} \boldsymbol{A}^{T} \boldsymbol{A}+\boldsymbol{I}\right)^{-1} \boldsymbol{C}^{*} \boldsymbol{y}
$$

which makes cost function $J$ minimum, where $\boldsymbol{I}$ is the identity matrix.

\section{EXPERIMENTAL SETUP}

Experimental tests have been carried out using one healthy motor and one motor with partially demagnetized (50\%) fault which is artificially introduced by special treatment. 50\% demagnetization of one pole pair is a representative case between incipient and serious damaged conditions. A laboratory scale test platform has been developed which mainly consists of two identical face to face motors, one is used as tested motor and the other is acted as load. The main technical specifications of the experimental PMSMs are listed in Table I. Experimental setting of demagnetization of one pole pair is shown in Fig. 1. Damaged magnet of a surfacemounted PMSM is demonstrated in Fig. 1(a). Fig. 1(b) presents the specific locations of 50\% demagnetization fault in the unfolded magnet array. Four different nonstationary operating scenarios have been investigated in this study for each tested PMSM.

TABLE I

MAIN TECHNICAL SPECIFICATIONS OF THE EXPERIMENTAL PMSMS

\begin{tabular}{cc}
\hline \hline Parameter & Value \\
\hline Manufacturer & ABB \\
Power converter model & DGV 700 \\
Rated voltage & $230 \mathrm{Vac}$ \\
Rated current & $2.9 \mathrm{~A}$ \\
Rated speed & $6000 \mathrm{r} / \mathrm{min}$ \\
Rated torque & $2.3 \mathrm{Nm}$ \\
Pole pairs & 3 \\
Stator slots & 18 \\
Nominal flux density & $0.85 \mathrm{~T}$ \\
\hline
\end{tabular}

The stator currents are measured using Tektronix A622 ac/dc current probe. Sampling frequency is $12 \mathrm{kHz}$, NI DAQ PCI-6251 is used for the data acquisition. A shaft encoder is mounted on the rotor shaft of PMSM to capture the rotational speed.

\section{RESULTS AND DisCUSSION}

The VKF based order tracking results of the healthy PMSM with speed profile from 6000 to $5550 \mathrm{r} / \mathrm{min}$ and nominal load are shown in Fig. 2. As can be seen in Fig. 2(a), the rotational speed varies from $6000 \mathrm{rpm}$ to $5550 \mathrm{rpm}$ during about 0.3 second, consequently, mechanical foundational frequency changes from $100 \mathrm{~Hz}$ to $92.5 \mathrm{~Hz}$. The stator current of phase $\mathrm{A}$ in this period is also shown in Fig. 2(b). There are three pole pairs in this machine, thus, the electrical foundational frequency $\mathrm{f}_{0}$ changes from $300 \mathrm{~Hz}$ to $277.5 \mathrm{~Hz}$. The $1 / 3,5 / 3$, $15 / 3$ order harmonics are tracked successfully by using the proposed VKF based order tracking as shown in Fig. 2(c). The envelopes of the tracked order are also displayed in this figure. 

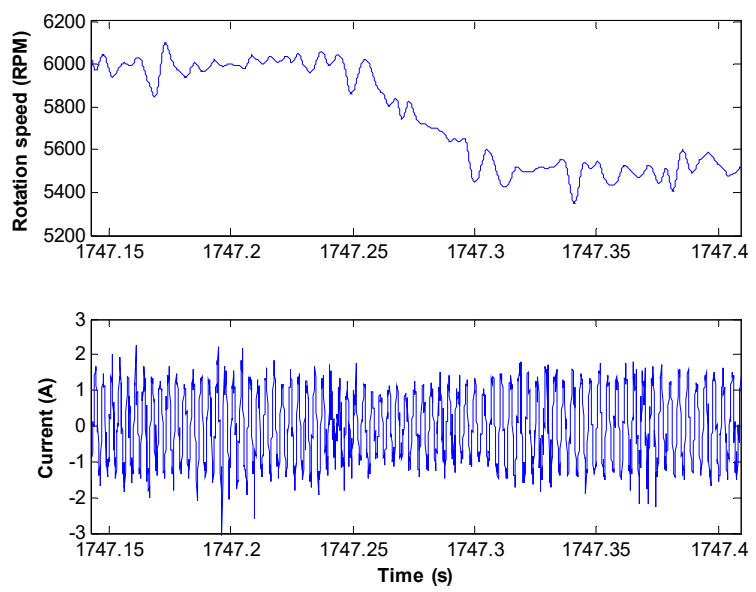

(a)
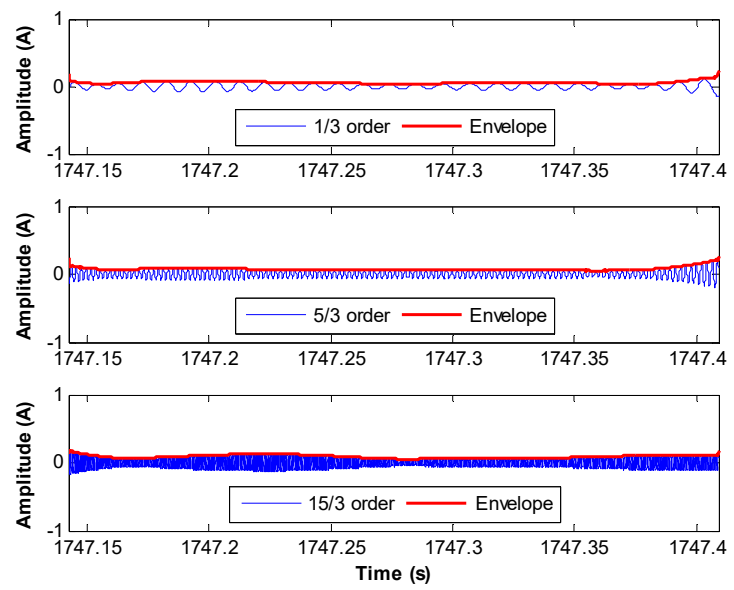

(b)

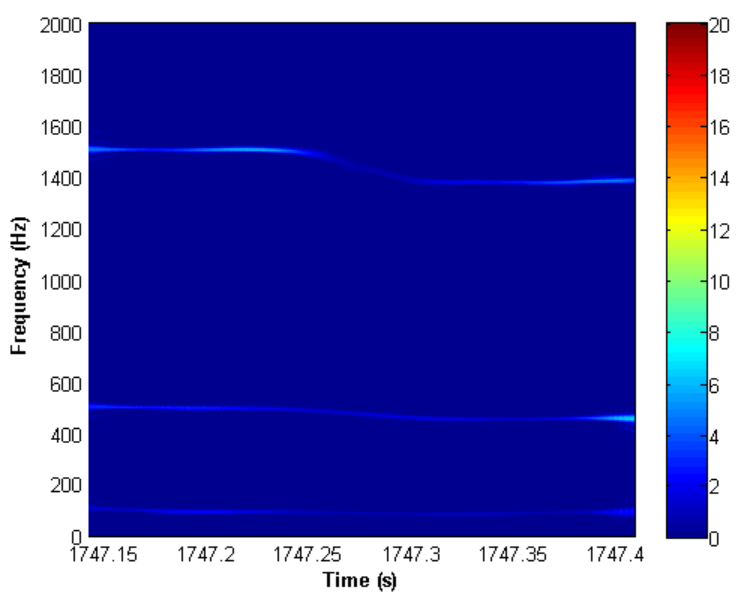

(c)

Fig. 2. PDFD results of healthy PMSM with slope speed profile from 6000 to $5550 \mathrm{r} /$ min. (a) Rotational speed and stator current. (b) Tracked 1/3,5/3 and $15 / 3$ orders and corresponding envelopes of stator current. (c) Choi-Williams time frequency distribution of the tracked orders.

Choi-Williams time frequency distribution of the tracked three characteristic orders is demonstrated in Fig. 2(d). The corresponding results of $50 \%$ demagnetized PMSM with the same speed profile from 6000 to $5550 \mathrm{r} / \mathrm{min}$ and nominal load are presented in Fig. 3. By comparing the results in these two
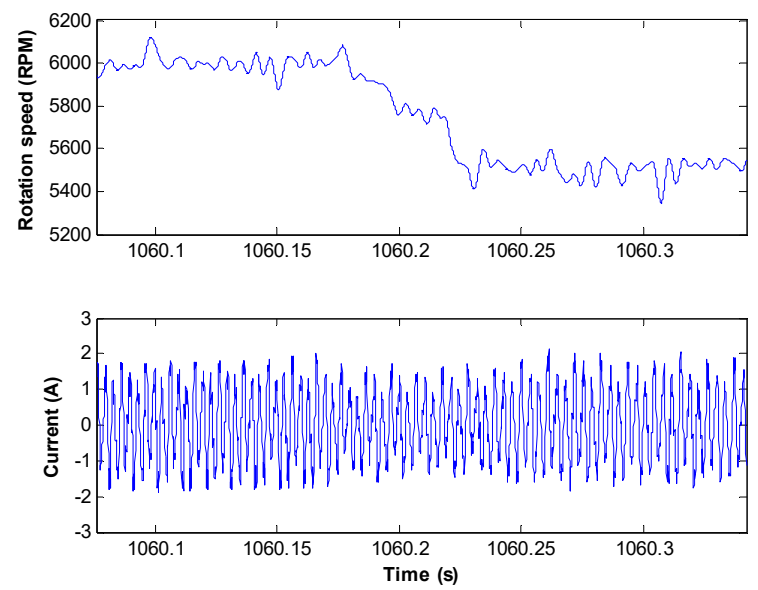

(a)
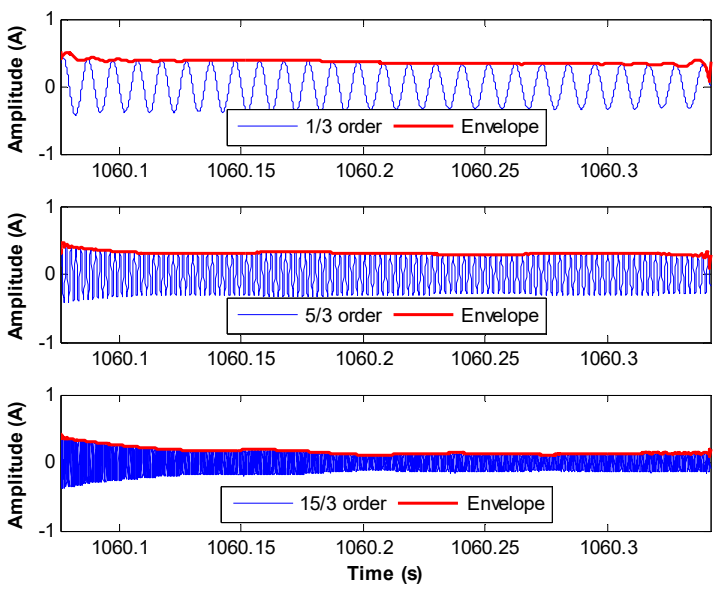

(b)

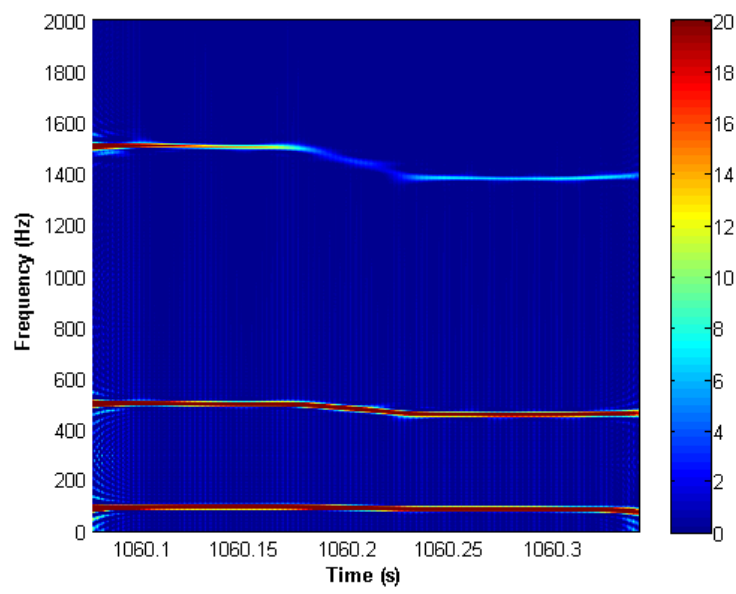

(c)

Fig. 3. PDFD results of 50\% demagnetized PMSM with slope speed profile from 6000 to $5550 \mathrm{r} / \mathrm{min}$. (a) Rotational speed and stator current. (b) Tracked $1 / 3,5 / 3$ and $15 / 3$ orders and corresponding envelopes of stator current. (c) Choi-Williams time frequency distribution of the tracked orders.

scenarios, it can be observed that the envelopes of $1 / 3,5 / 3$, $15 / 3$ orders of stator current in $50 \%$ demagnetization fault occasion are all higher than those of healthy occasions. Significant difference of Choi-Williams time frequency distributions of the tracked orders of these two cases can be 
observed easily.

TABLE II

ENVELOPE VALUE (RMS) OF FAULT CHARACTERISTIC ORDERS FOR PMSM WITH 50\% DEMAGNETIZATION OPERATING UNDER DIFFERENT SPEEDS AND LOADS CONDITIONS

\begin{tabular}{|c|c|c|c|}
\hline \multicolumn{4}{|c|}{ I: $6000-5550 \mathrm{r} / \mathrm{min}$, rated load } \\
\hline & $f_{0} / 3$ & $5 f_{0} / 3$ & $15 f_{0} / 3$ \\
\hline Healthy & 0.0615 & 0.0800 & 0.0961 \\
\hline $50 \%$ demagnetization & 0.3630 & 0.3130 & 0.1770 \\
\hline \multicolumn{4}{|c|}{ II: $6000-5550 \mathrm{r} / \mathrm{min}$, half-rated load } \\
\hline & $f_{0} / 3$ & $5 f_{0} / 3$ & $15 f_{0} / 3$ \\
\hline Healthy & 0.0585 & 0.0591 & 0.0556 \\
\hline $50 \%$ demagnetization & 0.2669 & 0.1952 & 0.0885 \\
\hline \multicolumn{4}{|c|}{ III: $3000-2500 \mathrm{r} / \mathrm{min}$, rated load } \\
\hline & $f_{0} / 3$ & $5 f_{0} / 3$ & $15 f_{0} / 3$ \\
\hline Healthy & 0.0566 & 0.0700 & 0.0334 \\
\hline $50 \%$ demagnetization & 0.1351 & 0.1283 & 0.0364 \\
\hline \multicolumn{4}{|c|}{ IV: $3000-2500 \mathrm{r} / \mathrm{min}$, half-rated load } \\
\hline & $f_{0} / 3$ & $5 f_{0} / 3$ & $15 f_{0} / 3$ \\
\hline Healthy & 0.0545 & 0.0387 & 0.0264 \\
\hline $50 \%$ dema & 0.1105 & 0.0957 & 0.0275 \\
\hline
\end{tabular}

Four operating conditions which assembles two different varying speed cases and two different load levels for each tested PMSM have been emulated in the experiments to verify the robustness of the proposed approach. The amplitudes of envelope of fault characteristic orders of stator currents for healthy and 50\% demagnetization PMSMs operating under different conditions are presented in Table II. It is observed that the amplitudes of envelopes of stator currents of $50 \%$ demagnetization all increase compared with those in healthy cases. Envelope change of $f_{0} / 3$ and $5 f_{0} / 3$ harmonics are more noticeable than that of $15 f_{0} / 3$ in all of these four conditions. Thus $1 / 3$ and $5 / 3$ orders are dominant components for extraction of fault indicator and PDFD of PMSMs. It should be noted that the fault indictors are more effective in high speed conditions, for instance, the envelope of $1 / 3$ order of $50 \%$ demagnetization PMSM is about six times of that in healthy PMSM in condition I, while it is only doubled in condition IV. Therefore, amplitude of the envelope is a good fault indicator. $50 \%$ demagnetization fault of a PMSM operating under various nonstationary conditions has been successfully detected using the proposed VKF based order tracking approach.

\section{CONCLUSION}

A novel methodology based on tracking the characteristic demagnetization fault orders of stator current by means of VKF has been proposed for the PDFD of PMSMs operating under nonstationary conditions. Only the fault related harmonics are tracked while the rest of components are removed as noise. Amplitude of envelopes of the fault characteristic orders has been used as fault indictors. The results demonstrate the potential of the proposed method for PDFD of PMSMs to be applied in industrial nonstationary applications, although the experimental machine is a relatively high speed machine (rated rotational speed is $6000 \mathrm{r} / \mathrm{min}$ ), the presented methodology for detecting demagnetization could also be applicable to low-speed machines.

\section{ACKNOWLEDGMENT}

This work was partially supported by Danish Agency for Science, Technology and Innovation, under Grant DSF-10094560 and China Scholarship Council. The authors would like to thank Julio César Urresty for the experimental setup.

\section{REFERENCES}

[1] K. C. Kim, S. B. Limn, D. H. Koo, and J. Lee, "The Shape Design of Permanenlt Magnet for Permanenlt Magnet Synchronous Motor Considernng Partial Demagnetization," IEEE Trans. Mag., vol. 42, no. 10, pp. 3485-3487, Sep. 2006.

[2] S. Yu and R. Tang, "Electromagnetic and mechanical characterizations of noise and vibration in permanent magnet synchronous machines," IEEE Trans. Mag., vol. 42, no. 4, pp. 1335-1338, Apr. 2006.

[3] J. R. Riba, J. A. Rosero, A. Garcia, and L. Romeral, "Detection of demagnetization faults in permanent-magnet synchronous motors under nonstationary conditions," IEEE Trans. Magn., vol. 45, no. 7, pp. 29612969, Jul. 2009.

[4] A. Garica Espinosa, J. A. Rosero, J. Cusido, L. Romeral, and J. A. Ortega, "Fault detection by means of hilbert-huang transform of the stator current in a PMSMwith demagnetization," IEEE Trans. Energy Convers., vol. 25, no. 2, pp. 312-318, Jun. 2010.

[5] T. Ishikawa, Y. Seki, and N. Kurita, "Analysis for Fault Detection of Vector-Controlled Permanent Magnet Synchronous Motor with Permanent Magnet Defect," IEEE Trans. Magn., vol. 49, no. 5, pp. 2331-2334, May 2013.

[6] J. C. Urresty, J. R. Riba, M. Delgado, and L. Romeral, "Detection of demagnetization faults in surface-mounted permanent magnet synchronous motors by means of the zero-sequence voltage component," IEEE Trans. Energy Convers., vol. 27, no. 1, pp. 42-51, Mar. 2012.

[7] J. Urresty, R. J. Riba, and L. Romeral, "A back-emf based method to detect magnet failures in PMSMs," IEEE Trans. Magn., vol. 49, no. 1, pp. 591-598, Jul. 2012.

[8] J. Urresty, R. Atashkhooei, J. R. Riba, L. Romeral, and S. Royo, "Shaft trajectory analysis in a partially demagnetized permanent-magnet synchronous motor," IEEE Trans. Ind. Electron., vol. 60, no. 8, pp. 3454-3461, Aug. 2013.

[9] Z. Yang, X. Shi, and M. Krishnamurthy, "Vibration monitoring of PM synchronous machine with partial demagnetization and inter-turn short circuit faults," in Proc. IEEE ITEC, Jun. 2014, pp. 1-6.

[10] W. le Roux, R. G. Harley, and T. G. Habetler, "Detecting rotor faults in low power permanent magnet synchronous machines," IEEE Trans. Power Electron., vol. 22, no. 1, pp. 322-328, Jan. 2007.

[11] S. Rajagopalan, W. Roux, T. G. Habetler, and R. G. Harley, "Dynamic eccentricity and demagnetized rotor magnet detection in trapezoidal flux (brushless DC) motors operating under different load conditions," IEEE Trans. Power Electron., vol. 22, no. 5, pp. 2061-2069, Sep. 2007.

[12] Z. Chen and E. Spooner, "Grid power quality with variable speed wind turbines," IEEE Trans. Energy Convers., vol. 16, no. 2, pp. 148-154, Jun. 2001.

[13] J. R. Riba, A. Garcia, and L. Romeral, "Demagnetization diagnosis in permanent magnet synchronous motors under non-stationary speed conditions," Electr. Power Syst. Res., vol. 80, no. 10, pp. 1277-1285, Oct. 2010.

[14] M. Delgado, A. Garcia, J. R. Riba, J. C. Urresty, and J. A. Ortega, "Feature extraction of demagnetization faults in permanent-magnet synchronous motors based on box-counting fractal dimension," IEEE Trans. Ind. Electron., vol. 58, no. 5, pp. 1594-1605, May 2011.

[15] H. Herlufsen, S. Gade, H. Konstantin-Hansen and H. Vold, "Characteristics of the Vold/Kalman order tracking filter," in Proc. IEEE Int. Conf. Acoust., Speech, Signal Process., 2000, pp.38953898.

[16] J. Tuma, P. Kočí, "Vold-Kalman order tracking filtering in rotating machinery," in Proc. of ICCC, May, 2001. pp. 143-146. 